\title{
Design, Analysis and Optimization of Space Frame Chassis
}

\author{
Anurag More ${ }^{\# 1}$, Chetan Chavan ${ }^{\# 2}$, Nikhil Patil ${ }^{\# 3}$, Prof. K. Ravi ${ }^{* 4}$ \\ ${ }^{\#}$ M.Tech Automotive Engineering, School of Mechanical and Building Sciences, \\ VIT University, Vellore \\ *Assistant professor, School of Mechanical and Building Sciences, \\ VIT University, Vellore, Tamil Nadu, India. \\ 1 anuragmore1@gmail.com \\ 2 chetanchavan97@gmail.com \\ ${ }^{3}$ nikhil.n.patil05@gmail.com
}

\begin{abstract}
Conventionally, chassis is made up of aluminium alloy and AISI 1018 steel. As the level of progress in improving the efficiency of engine has come to a saturation point, it is important to study different aspects to enhance the overall performance of an automobile. As chassis forms the entire base to mount all the automotive components like engine, transmission and braking system, it must be able to take the entire weight of components efficiently. Using steel grades might give us necessary strength but it does contribute to increase in weight. Considering the fact that car to be manufactured is a sports car, it is necessary to eliminate the factors which may hamper the performance of a car. So, one of the most important alternative is to change the material and it must be chosen in such a way that it imparts necessary strength and also keep entire weight under limit. The main purpose of this paper is to test the carbon fiber for a space frame chassis model to withstand all the forces experienced under realistic conditions. A complete analysis of a space frame chassis by using carbon fiber is carried out so as to compare it with steel and to optimize it by reducing its cross section so that the overall weight can be lowered ultimately ensuing improved performance.
\end{abstract}

Keyword- Automobile, Carbon fiber, Chassis, Transmission, Impulse-momentum.

\section{INTRODUCTION}

Building an unrelenting and light weight chassis is the most important factor to be considered for any high performance automobile. These characteristics features make a car to accomplish its destination to be on the top in the races. Here, well designed firm and agile chassis provides better performance in terms of both acceleration and braking. In order to achieve this the root of design starts from the type of material to be used in a chassis. Conventionally, SAE chassis are mostly manufactured by using AISI 1018 Steel or Aluminium alloys. But due to increase in the level of toughness in performance of automobiles, there has been a sudden shift on research for the use of composite materials.

A carbon fiber chassis acts as a spine of an automobile confining all together, making sure that all the members are safe by assuring structural steadiness [1]. A high speed car makes use of various aspects of performance related things to achieve torsional rigidity, powerful engine and harder suspension setup. Maclaren MP4/1 Formula 1 race car was the headmost to make use of carbon fiber monocoque chassis [2]. Carbon fiber tubes bestow excellent structural strength and gives rigidity to a vehicle [3]. The model presented in this paper is space frame chassis. Space frame chassis lies in between ladder type and monocoque type chassis. In this smaller members are connected together one by one to form a larger frame. This type of chassis is some-what similar to truss bridge in which the triangular members are always under tension and compression [4]. Besides, maintenance and repairing of space frame chassis are on the lower side. Due to ease in manufacturing trend of using this type of chassis has been increased. It has been concluded that use of materials like AISI 1018 Steel and Chromoly 4130 yielded good results from safety aspects. So here the main focus of the paper is to make use of carbon fiber for space frame chassis design. The objective is to test the designed chassis by using realistic impact and loading conditions. Further comparing the results with conventionally designed chassis.

To optimize the designed model and to make use of carbon fiber to its fullest, the cross section area of pipe will be reduced depending on the availability of standard size. A comparative study is carried out by using carbon fiber of lesser thickness for the same loading conditions as that of conventional chassis. How efficient is the carbon fiber to withstand all the forces experienced during cornering and impact is concluded in this paper.

Mat, Mohd, Hanif, and Amir Radzi Ab Ghani [5] emphasized on building a chassis that must be light weight and it must have strength to safeguard driver during crash. The material chosen was mild steel. Chassis was developed by using the combination circular and square cross sections. Abhijeet Das [6] aimed to develop Supra SAE chassis. Material selected was Chromoly Steel due to its structural properties and excellent stiffness. 
Ravindra Laxman Gaikwad, Prathamesh Vishwas Waghmare, Kapil Kanhaiyalal Purohit, Akshay Mukesh Mutake [7] focused on developing a reliable and low cost chassis. AISI 4130 Steel was used due to its light weight nature. Results of this analysis concluded that chassis was able to withstand $10 \mathrm{G}$ forces with deformation of $5.1 \mathrm{~mm}$. Yembarwar Shubham et al. [8] developed a space frame chassis by considering of road usage. Chromoly steel 4130 was assigned to chassis for carrying out analysis work. D.Lavanya, G.Guru Mahesh, V.Vijay, Dr.C. Yuvaraj [9] designed a single seat race car using AISI 1018 Steel. The results obtained were satisfactory concluding with actual implementation of design. Mahendra M., B.S.Praveen Kumar, Puttaswamaiah, G.S.Prakash [10] focused on analyzing SAE car chassis dynamically with use of LS- Dyna software. Aluminium alloy and different steel grades were used for analysis from which he concluded that steel grades have better strength to withstand the forces.

Before submitting your final paper, check that the format conforms to this template. Specifically, check the appearance of the title and author block, the appearance of section headings, document margins, column width, column spacing and other features.

\section{DESIGN METHODOLOGY}

There are various types of frames that can be used for the formula race car like monocoque chassis, ladder chassis and space frame type of chassis. But particularly most preferable design which can be used for formula racing competitions are tubular space frame type of chassis. In these type of chassis, a number of tubes are joined together to form a final structure. Since the manufacturing of these type of chassis is relatively simple and cost effective, space frame chassis are selected over monocoque chassis. Flow chart in Figure 1 represents the steps that has been followed to design and analyze the chassis. . Flow chart in Figure 1 represents the steps that has been followed to design and analyze the chassis.

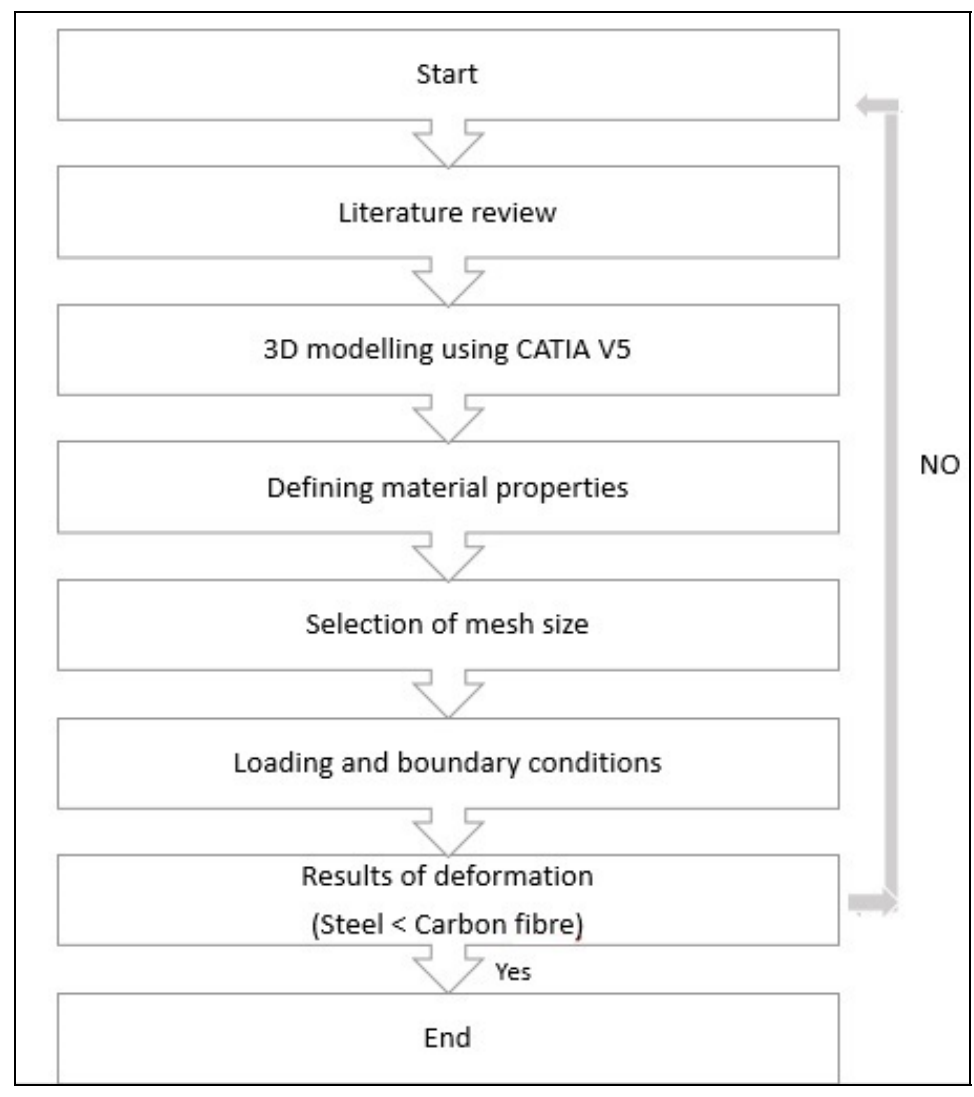

Fig. 1. Design Methodology

\section{A. Basic design of chassis}

Safety, ergonomics, strength are the factors which are to be considered while designing a chassis. Safety of driver is the most important factor to be considered while designing a vehicle. Overall performance of the vehicle also depends on the drivability of the driver. Hence, by ensuring most of the controls within the reach of the driver the overall performance can be improved. The different design considerations to be taken into account while designing a space frame. Connections must be properly triangulated so as to ensure the rigidity of chassis. Main hoop must be 
perfectly vertical for easy mounting of driver's back rest in inclined position. Lower side members must have at least $100 \mathrm{~mm}$ offset from the base of driver's seat. Considering the comfort of driver inside cabin, angle between thigh and stomach must not be greater than $45^{\circ}$. Aero exclusion must be provided at front end. Wing location at front bottom end.

By taking into consideration above parameters, the basic design of chassis was constructed on CATIA-V5 software. The cross section of pipe was selected from the standard manual and chassis with $30 \mathrm{~mm}$ outer diameter was designed. The model was then imported to ANSYS 15 for finite element analysis. Following figure represents a completely designed space frame chassis.

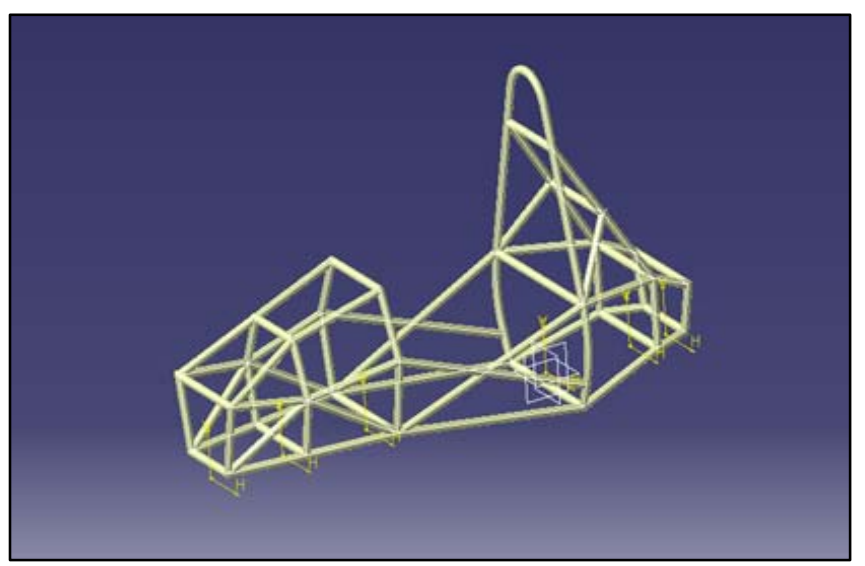

Fig. 2. 3D model of space frame chassis

\section{B. Material selection}

Material selection plays an important role in providing the vehicle a required strength, safety, with low weight. Also, one of the most factor of concern is the availability of the material. Conventionally used material for the chassis is AISI 1018 steel because of its availability and low cost [11]. But the prime concern related to this is its weight. In order to improve its performance by reducing is weight, alternative material like alloys and composites must be put into use. This paper represents sustainability of composite material like carbon fiber under the same loading conditions as that of steel.

Carbon fiber is formed by closely packed carbon atoms which are bonded together in a crystal. The second part is the advantages of the carbon fiber which includes:

1. Higher strength to weight ratio.

2. Better corrosion resistance and chemical stability.

3. Good fatigue resistance and tensile strength.

\section{Material Properties}

TABLE I. Material properties of AISI 1018 Steel

\begin{tabular}{|l|l|}
\hline Properties & Value \\
\hline Young's modulus $(\mathrm{Pa})$ & $2.0 \mathrm{e}+11$ \\
\hline Poisson's ratio & 0.3 \\
\hline Tensile Yield Strength $(\mathrm{Pa})$ & $2.5 \mathrm{e}+08$ \\
\hline UTS $(\mathrm{MPa})$ & $4.6 \mathrm{e}+08$ \\
\hline Density $\left(\mathrm{Kg} / \mathrm{m}^{3}\right)$ & 7850 \\
\hline
\end{tabular}


TABLE II. Material properties of Carbon Fiber

\begin{tabular}{|l|l|}
\hline \multicolumn{1}{|c|}{ Properties } & \multicolumn{1}{c|}{ Value } \\
\hline Young's modulus $(\mathrm{Pa})$ & $7.0 \mathrm{e}+10$ \\
\hline Poisson's ratio & 0.1 \\
\hline Tensile Yield Strength $(\mathrm{Pa})$ & - \\
\hline UTS $(\mathrm{MPa})$ & $7.58 \mathrm{e}+08$ \\
\hline Density $\left(\mathrm{Kg} / \mathrm{m}^{3}\right)$ & 1600 \\
\hline
\end{tabular}

\section{Boundary conditions and forces calculations}

After the selection of the material for the designed frame, it is necessary to check the performance of the frame under various impact conditions. The designed frame must withstand all the impact as well as torsional conditions while providing safety to the driver and while having very less deformation of the members.

Designing of chassis was carried out on CATIA V5 and then the model was imported to ANSYS Workbench for simulation. Front, rear, side, torsional and rollover analysis is carried out in order to test the chassis durability.

Mass of vehicle is assumed to be $250 \mathrm{Kg}$.

Impact time is considered as 0.20 seconds

\section{Front Impact Analysis-}

A car is considered to be moving at a speed of $27.78 \mathrm{~m} / \mathrm{s}$ and suffers a head on collision with a rigid and nondeformable barrier.

Impact force $=($ Mass $*$ Change in momentum $) /$ Impact time

We get,

Impact force $=34712.5 \mathrm{~N}$

Analysis is carried out by fixing the rear bottom connections below driver's seat.

Rear Impact Analysis:

Considering chassis experiences a force of $4 \mathrm{G}$ at rear end during impact.

Total rear impact force $=10000 \mathrm{~N}$

For rear impact test, front end of chassis is constrained.

Side Impact Analysis:

Considering chassis experiences $3 \mathrm{G}$ load during side impact.

Total force $=7500 \mathrm{~N}$

Exactly opposite side of applied load is constrained.

Torsional Analysis:

Considering chassis experiences $2.5 \mathrm{G}$ force.

Total load $=6250 \mathrm{~N}$

Diagonally opposite members of extreme ends are considered for constraining, while loading is carried out on opposite member to the fixed member to have twisting action of chassis. Considering the results of analysis for AISI 1018 Steel for $30 \mathrm{~mm}$ outer diameter and $1.5 \mathrm{~mm}$ thickness as a benchmark, further tests were completed by varying the cross section area.

The main intension behind this process is to find out up to which, the cross section area can be reduced to achieve same deformation as that of steel. Sizes are selected from a standard manufacturer's catalogue. 
Finite Element Analysis:

Designed model from CATIA V5 was imported to ANSYS 15 for the analysis purpose. Following results were obtained from the analysis:

\section{Considering Material as Steel:}

For $30 \mathrm{~mm}$ outer diameter and $1.5 \mathrm{~mm}$ thickness

Front impact

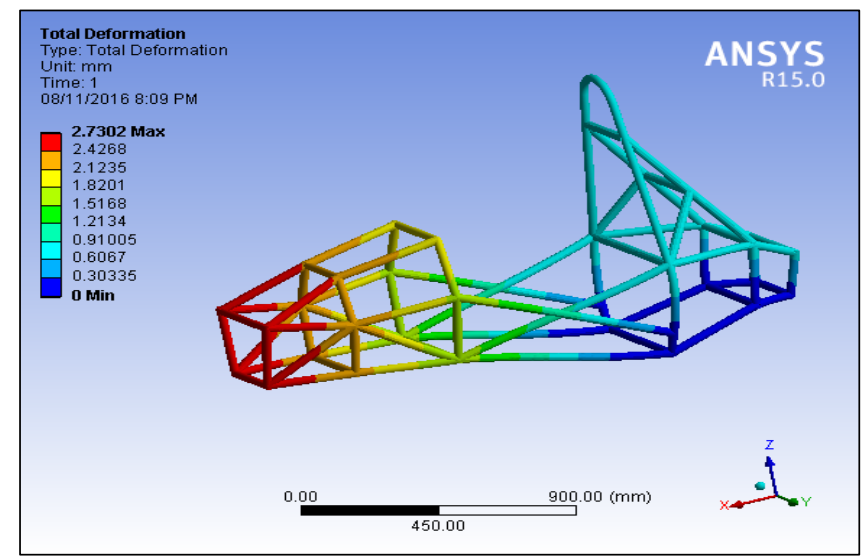

Fig. 3. Deformation for front impact

Force must be distributed uniformly at front end in order to get accurate results. So the total force was divided by 4 so that each of the 4 front nodes take up equal force. The deformation achieved was $2.7302 \mathrm{~mm}$.

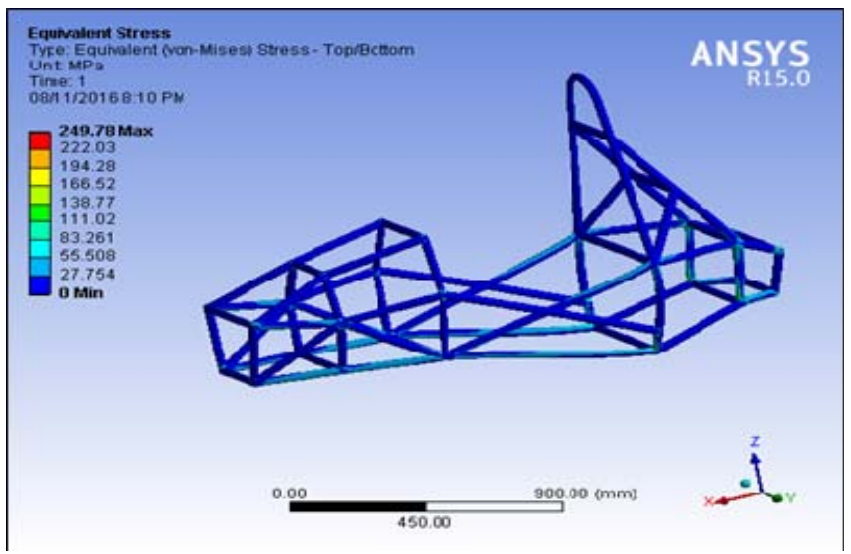

Fig. 4. Von-mises stress for front impact

Von-mises stress induced after the front impact was recorded as $249.78 \mathrm{Mpa}$.

Rear impact:

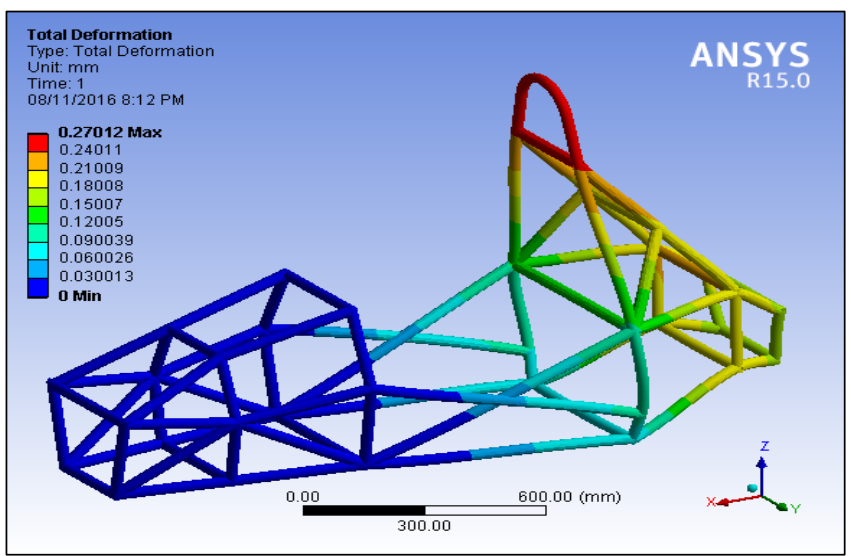

Fig. 5. Deformation for rear impact 
Taking into consideration uniform distribution of load, the rear impact test yielded a deformation of $0.27012 \mathrm{~mm}$.

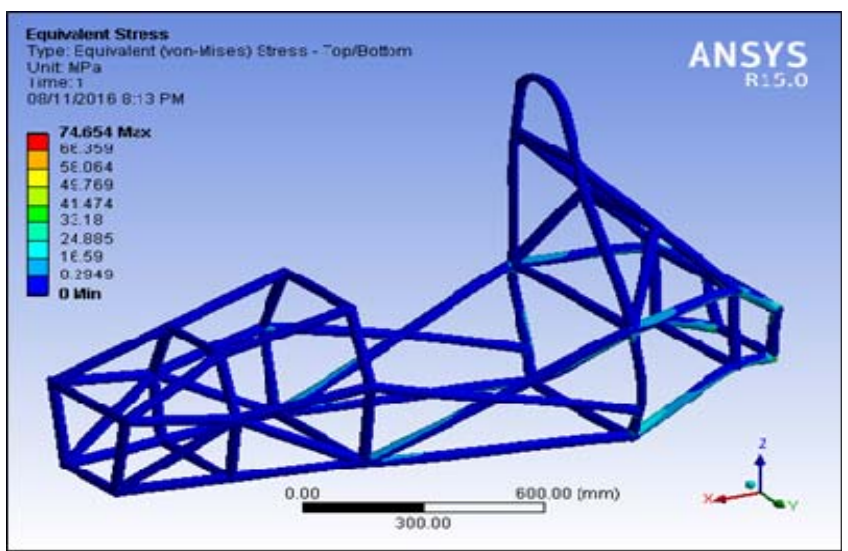

Fig. 6. Von-mises stress for rear impact

Stress induced of rear impact observed was $74.654 \mathrm{Mpa}$

Side impact:

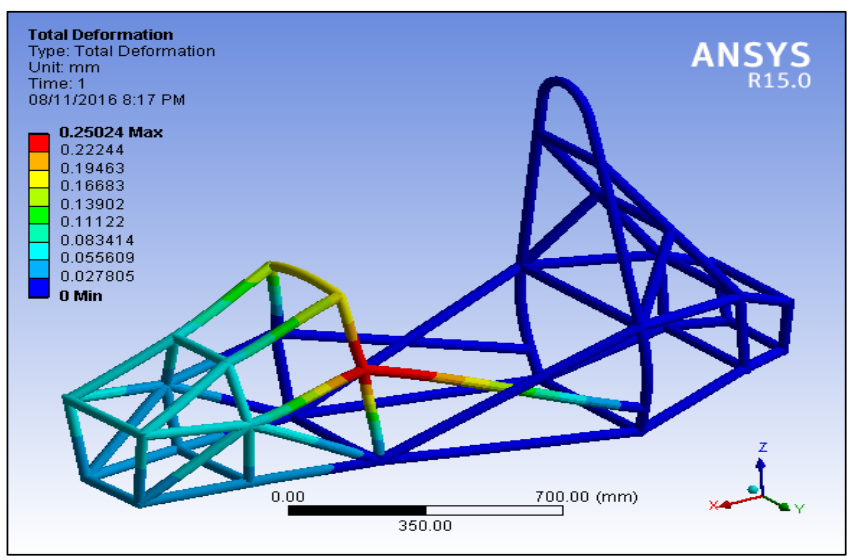

Fig. 7. Deformation for side impact

Constraining the opposite bars of the applied load, the test conducted yielded the deformation of $0.26024 \mathrm{~mm}$.

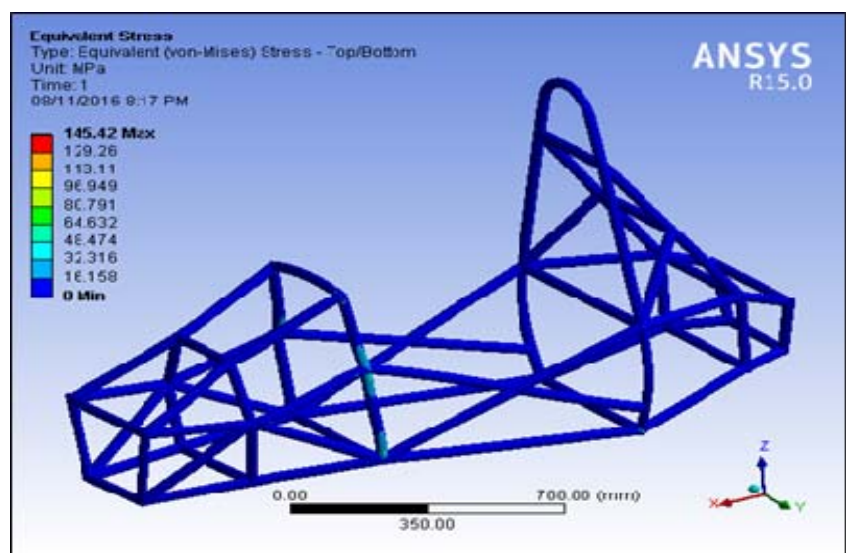

Fig. 8. Von-mises stress for side impact

Stress induced observed for side impact test was 145.42 . 
Torsional test:

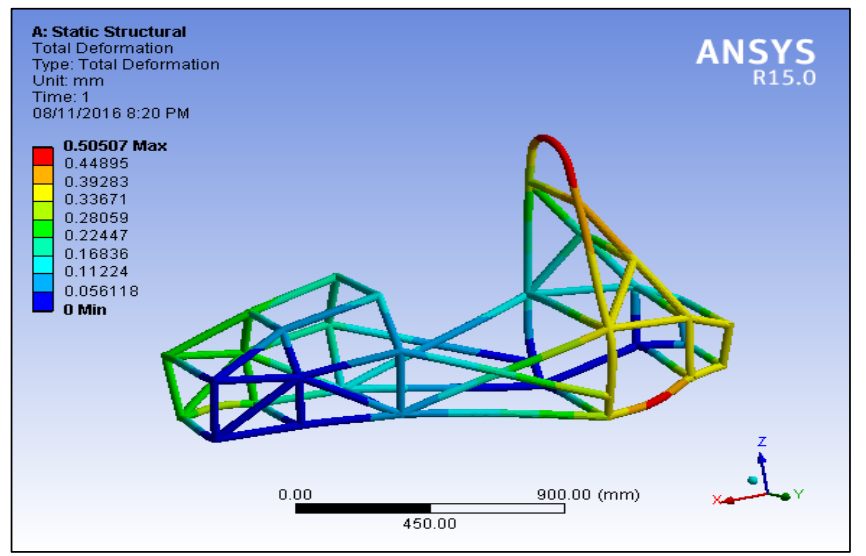

Fig. 9. Deformation for torsional test

Loading the diagonally opposite members to form a twist and constraining the opposite members of the applied load, we get deformation of $0.50507 \mathrm{~mm}$.

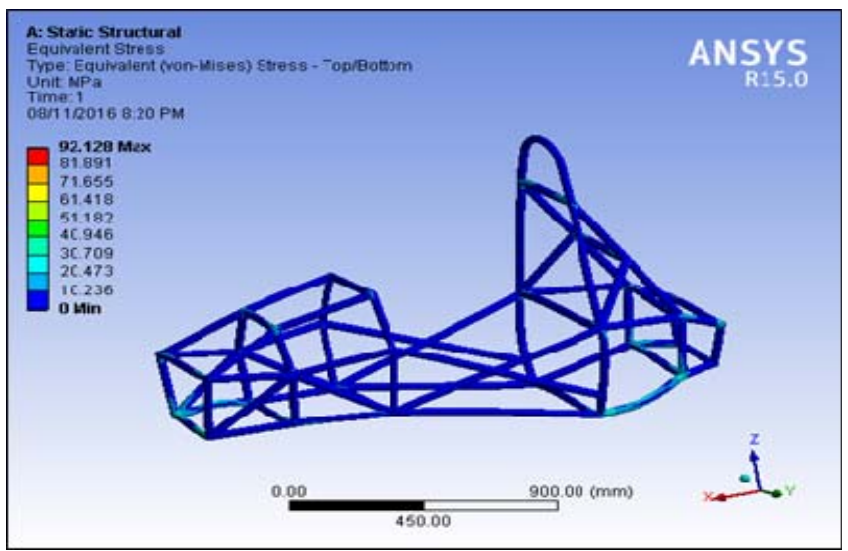

Fig. 10. Von-mises stress for torsional stress

Stress induced was 92.128 Mpa for torsional loading conditions.

\section{Considering material as Carbon Fiber:}

Similarly, tests were conducted for carbon fiber of $30 \mathrm{~mm}$ outer diameter and thickness of $1.5 \mathrm{~mm}$. The results are as follows-

Front impact:

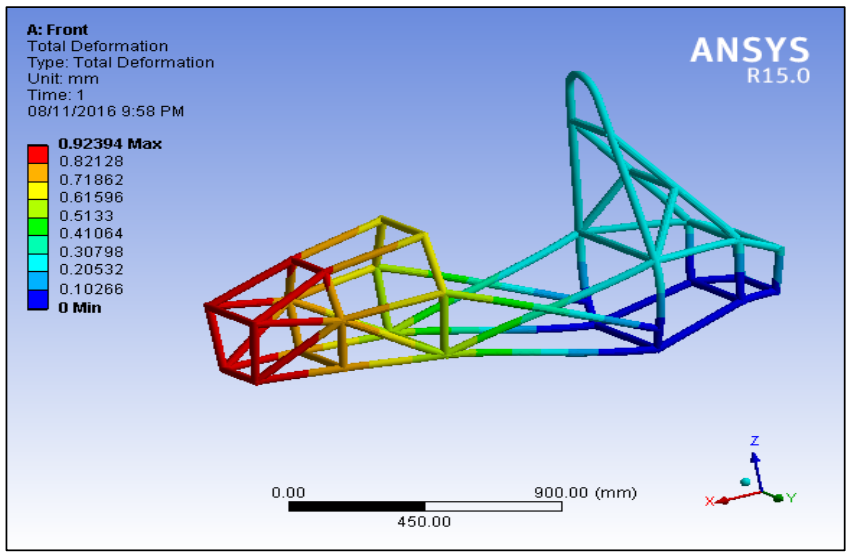

Fig. 11. Deformation for front impact 
Using same method, deformation of carbon fiber observed was $0.92393 \mathrm{~mm}$.

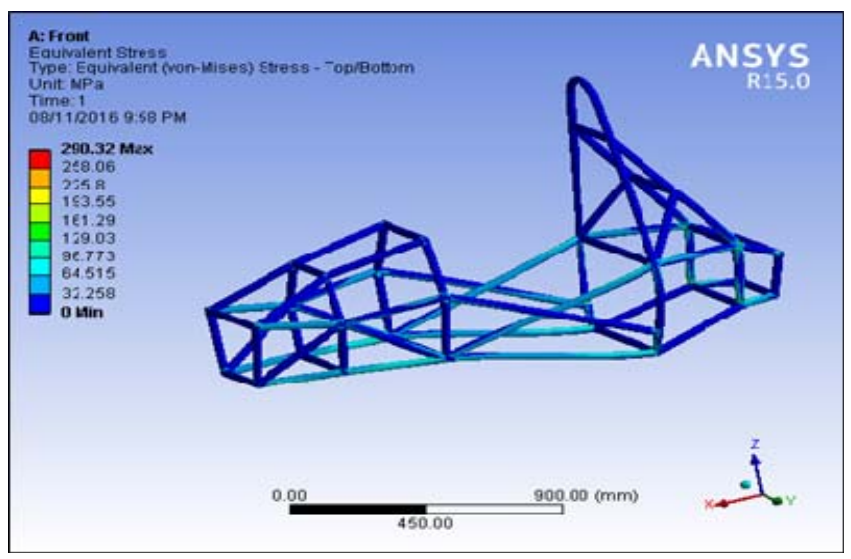

Fig. 12. Von-mises stresses for front impact

Stress induced in chassis observed for carbon fiber was 290.32 Mpa. Comparing it with the ultimate strength of carbon fiber, it can be stated as the stress was within acceptable limits.

\section{Rear impact:}

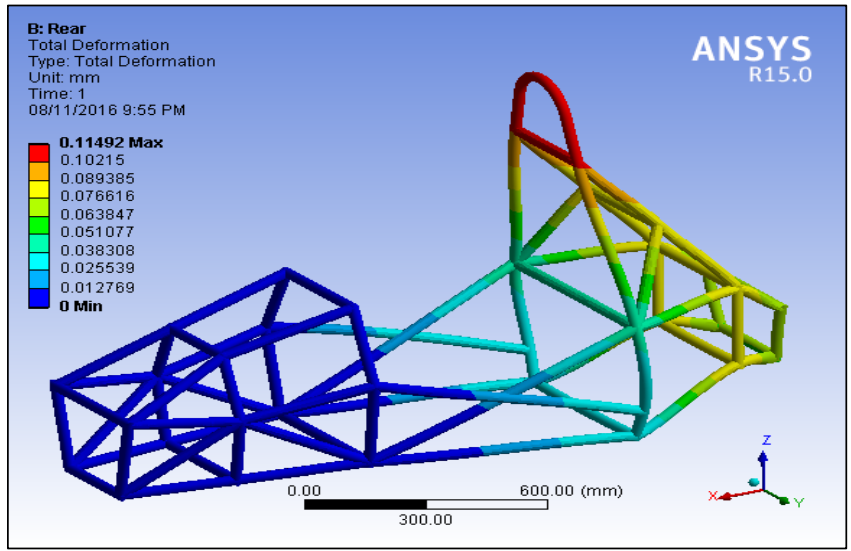

Fig. 13. Deformation for rear impact

Deformation observed for rear impact was $0.11492 \mathrm{~mm}$.

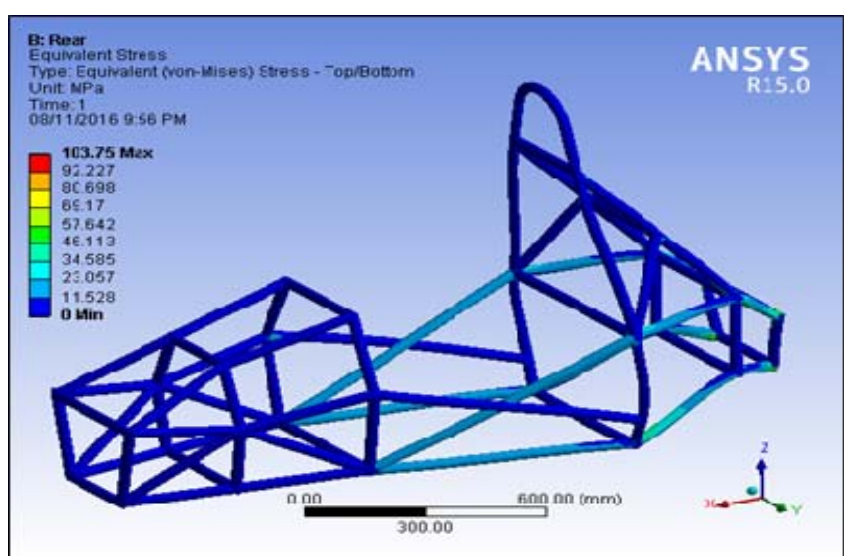

Fig. 14. Von-mises stress for rear impact

Stress induced for carbon fiber under rear impact was observed lowest of all as $103.75 \mathrm{Mpa}$. Hence, the design is safe. 
Side impact:

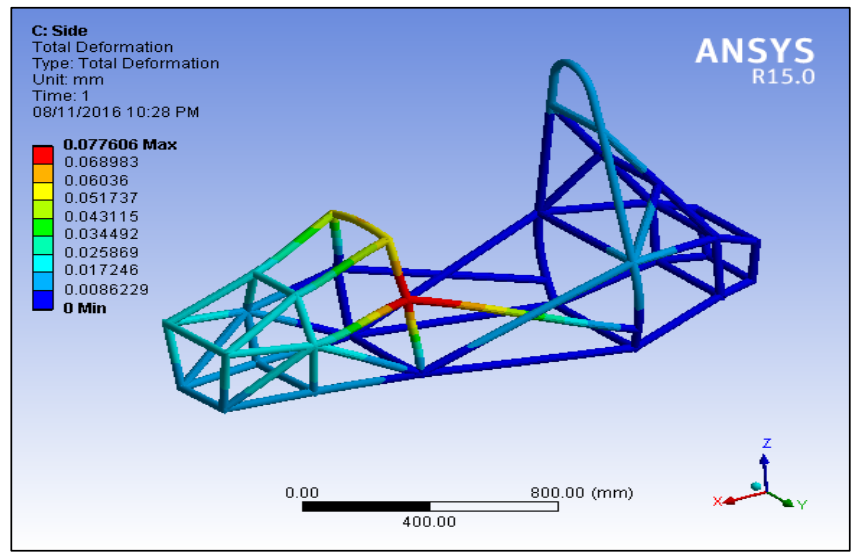

Fig. 15. Deformation for side impact

Side impact test yielded lowest deformation of all the test conducted. Triangulated end of side bar deflects by $0.077606 \mathrm{~mm}$.

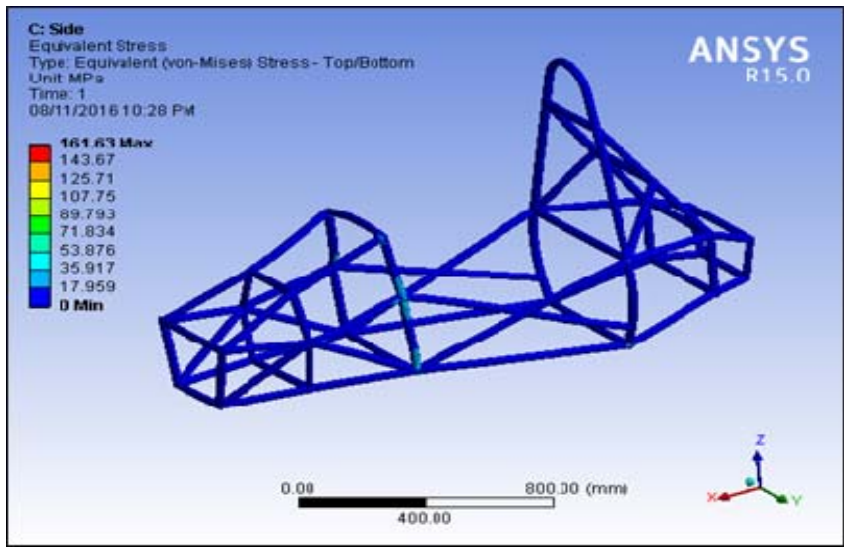

Fig. 16. Von-mises stress for side impact

Stress induced observed was $161.63 \mathrm{Mpa}$.

Torsional test:

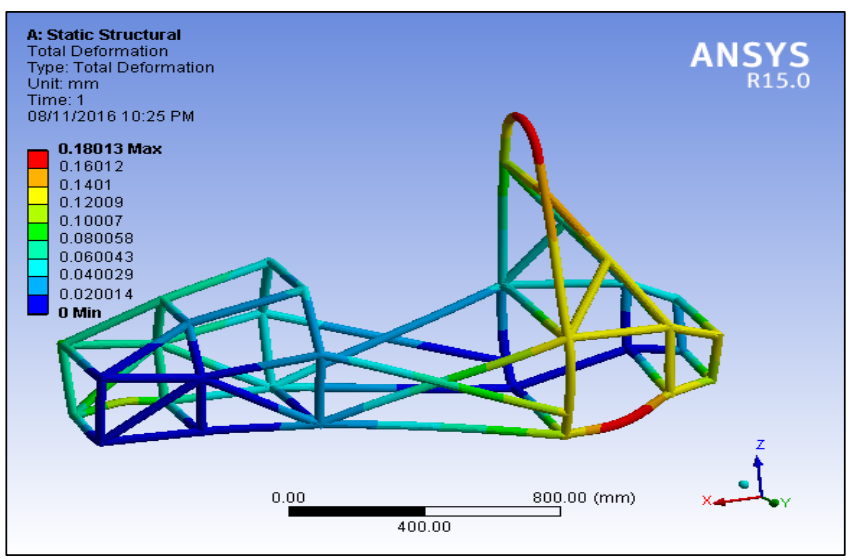

Fig. 17. Deformation for torsional test

The designed chassis was able to withstand the twist yielding a deformation of $0.18013 \mathrm{~mm}$. 


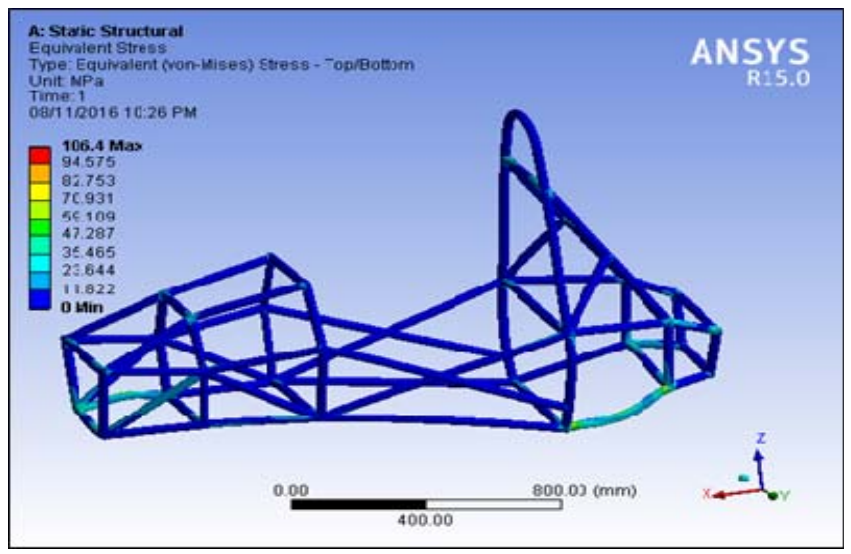

Fig. 18. Von-mises stress for torsional test

Stress induced for twist of chassis was observed to be 106.4 Mpa.

From the results of the analysis it is clear that the deformation of carbon fiber is much lesser than that of steel for same cross section. Hence the next step is to reduce the cross section of the pipe for the same loading conditions. For optimization of chassis by reducing the cross section, different standard cross sections of carbon fiber pipes were selected so as to compare the deformation with standard steel results. The sizes of carbon fiber pipes selected from standard manufacturer's catalogue.

TABLE III. Selection of pipe sizes

\begin{tabular}{|l|c|}
\hline Carbon Fiber & Sizes \\
\hline Pipe 1 (reference) & $\mathrm{OD}=30 \mathrm{~mm}, 1.5 \mathrm{~mm}$ thick \\
\hline Pipe 2 & $\mathrm{OD}=29 \mathrm{~mm}, 1.25 \mathrm{~mm}$ thick \\
\hline Pipe 3 & $\mathrm{OD}=25 \mathrm{~mm}, 1.5 \mathrm{~mm}$ thick \\
\hline Pipe 4 & $\mathrm{OD}=23.5 \mathrm{~mm}, 1.75 \mathrm{~mm}$ thick \\
\hline
\end{tabular}

Conducting same tests for all above listed pipes, deformations observed for pipe 2 for all the impact tests, were less than that of steel. Testing pipe 3 for same loading conditions it was observed that the deformation for side impact test observed was higher than that of steel.

Side impact test for pipe 4:

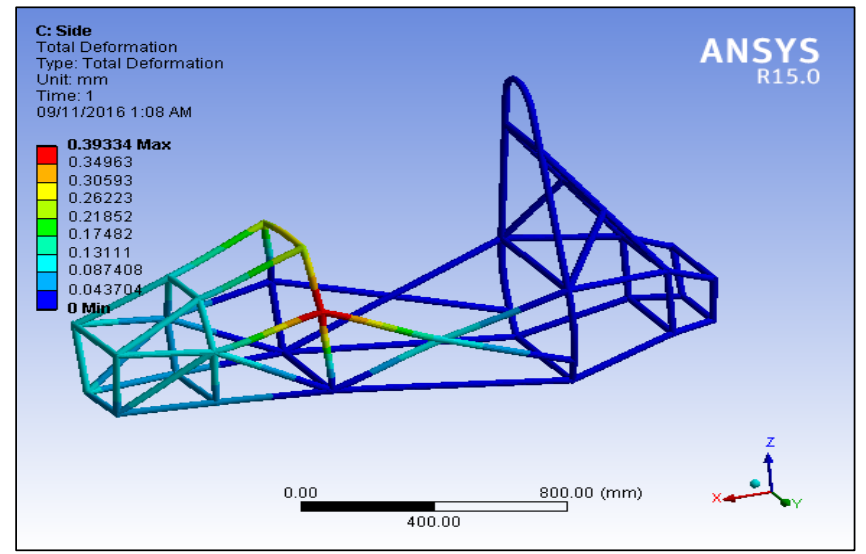

Fig. 19. Deformation for side impact

The deformation observed for side impact test was higher than steel. 


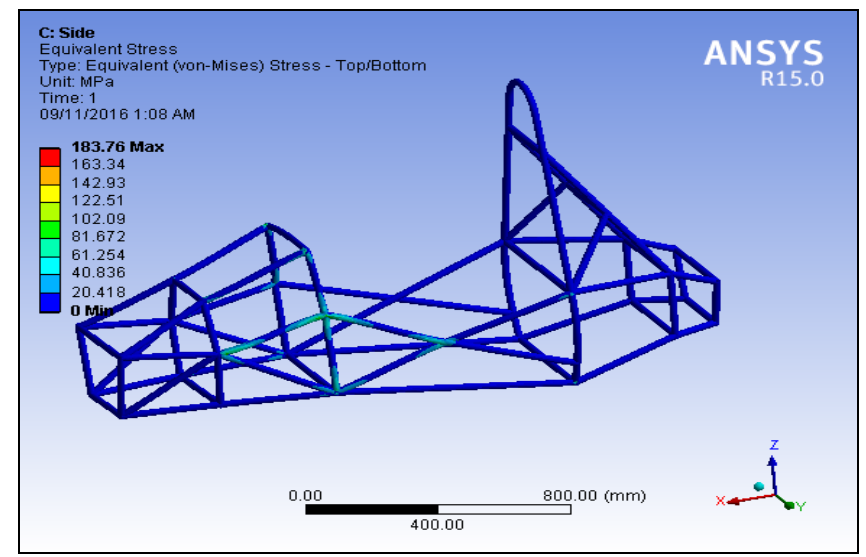

Fig. 20. Von-mises stress for side impact

Stress induced was $183.76 \mathrm{Mpa}$ for side impact test of pipe 4.

TABLE IV. Comparison of steel with carbon fiber pipe 4

\begin{tabular}{|l|c|c|}
\hline Tests & $\begin{array}{c}\text { AISI 1018 Steel } \\
\text { Deformation (mm) }\end{array}$ & $\begin{array}{l}\text { Carbon fiber pipe 4 } \\
\text { Deformation (mm) }\end{array}$ \\
\hline Front & 3.2562 & 1.5544 \\
\hline Rear & 0.40692 & 0.19905 \\
\hline Side & $\mathbf{0 . 2 7 0 7 7}$ & $\mathbf{0 . 3 9 3 3 4}$ \\
\hline Torsional & 0.63953 & 0.34185 \\
\hline
\end{tabular}

A step by step analysis has been carried on different pipe sizes of carbon fiber as it is important to investigate its behavior under different impact conditions. The main focus of this paper has been on optimization by reducing the cross section area of carbon fiber pipe because it is costly whereas for the same thickness, carbon fiber is much stronger than steel. So decreasing cross section area will reduce the cost of pipes while replacing steel with those carbon fiber pipes will ultimately reduce the entire weight of chassis.

From the table it is clear that the deformation observed for side impact test for pipe 4 was higher than steel. From this we can conclude that pipes 1, 2 and 3 gave less deformation compared to standard steel results. Implementation of pipe 3 will optimize the overall weight and strength of chassis as the cross sectional area reduction achieved was $17.54 \%$.

\section{CONCLUSION}

1. From the analysis, it was observed that, for the same cross section of $\mathrm{OD}=30 \mathrm{~mm}$ and thickness of $1.5 \mathrm{~mm}$, deformation of carbon fiber was very less as compared to that of the steel.

2. Hence to optimize the cross-section, i.e. to achieve the same deformation as that of the steel, diameter of carbon fiber was reduced, so that the optimum size can be selected.

3. It was observed that, for the pipe size of outer diameter $23.5 \mathrm{~mm}$ and thickness of $1.75 \mathrm{~mm}$, the deformation observed in case of carbon fiber was greater than that of the steel for side impact test.

4. From this result, it can be concluded that, the overall weight of chassis can be minimized by using pipe 2 and pipe 3, as they keep deformation less than steel.

5. Fact regarding pipe 4 results is that, the deformation observed may be slightly higher than steel, but it is still a safe chassis. As the main intent of this work is just to study up to which the reduction in cross section for carbon fiber gives less deformation compared to steel so as to replace the steel by carbon fiber for better optimization.

6. From the analysis performed by varying the pipe sizes for chassis, a maximum reduction in cross sectional area achieved was $17.54 \%$ for the same loading conditions. So from this we can conclude that the strength and weight of space frame chassis has been optimized to certain extent up to which it will create an impact when put to the test. 


\section{ACKNOWLEDGMENT}

This work was supported by Prof. Ravi. K from the School of Mechanical and Building Science (M. Tech in Automotive Engineering), VIT University. The valuable suggestions that we received helped us to boost our knowledge regarding this subject.

\section{REFERENCES}

[1] Dardinski, A., \& Norcross, J. Carbon fiber monocoque chassis for race cars.

[2] 1981 Formula 1 McLaren MP4/1. McLaren. (Online Article) http://www.mclaren.com/formula1/heritage/cars/1981-formula-1mclaren-mp4-1/

[3] Eurenius, C. A., Danielsson, N., Khokar, A., Krane, E., Olofsson, M., \& Wass, J. Analysis of Composite Chassis. Bachelor Thesis.

[4] Sinha, M. (2016). Design of a space frame race car chassis entailing rectification of preceding flaws with apt ergonomic considerations, material selec-tion and impact analysis. International Journal of Innovative Research in Science, Engineering and Technology, 5(4), $5686-5694$.

[5] Mat, M. H., \& Ghani, A. R. A. (2012). Design and analysis of 'Eco'car chassis. Procedia Engineering, 41, $1756-1760$.

[6] Das, A. (2015). Design of Student Formula Race Car Chassis. International Journal of Science and Research, 4(4), 2571-2575. M. Shell.

[7] Gaikwad, R. L., Waghmare, P. V., Purohit, K. K., \& Mutake, A. M. (2016). Design of student formula-1 vehicle systems. International Journal of Advance Research in Science and Engineering, 495-504.

[8] Yembarwar, S., Kamble, B., Pande, P., \& Wankhade, A. Design and finite element analysis of roll cage of all-terrain vehicle. International Journal of Research In Science \& Engineering, 2(3), 30-37.

[9] Lavanya, D., mahesh, G. G., ajay, V., \& yuvaraj, C. (2014). Design and analysis of a single seater race car chassis frame. International Journal of Re-search In Aeronautical and Mechanical Engineer-ing, 2(8), 12-23.

[10] Mahendra, H. M., Praveen Kumar, B. S., Puttaswamaiah, S. \& Prakash, G.S. (2014). Design and crash analysis of a rollcage for formula SAE race car. Interna-tional Journal of Research in Engineering and Technology, 3(7), 126-130.

[11] Chaudhari, K., Joshi, A., Kunte, R., \& Nair, K. (2013). Design and development of roll cage for an all-terrain vehicle. International Journal on Theoretical and Applied Research in Mechanical Engineering, 2(4), 49-54.

\section{AUTHOR PROFILE}

Anurag More M. Tech. in Automotive Engineering, School of Mechanical and Building Sciences, VIT University, Vellore-632014, Tamil Nadu, India.

Chetan Chavan M. Tech. in Automotive Engineering, School of Mechanical and Building Sciences, VIT University, Vellore-632014, Tamil Nadu, India.

Nikhil Patil M. Tech. in Automotive Engineering, School of Mechanical and Building Sciences, VIT University, Vellore-632014, Tamil Nadu, India.

Prof. Ravi. K Assistant Professor, School of Mechanical and Building Sciences, VIT University, Vellore632014, Tamil Nadu, India. 